Original article

\title{
Leptospirosis in Wardha District, Central India-Analysis of hospital based surveillance data
}

\author{
Pradeep Deshmukh ${ }^{\mathrm{a}}$, Rahul Narang ${ }^{\mathrm{b}, *}$, Jyoti Jain ${ }^{\mathrm{c}}$, Manish Jain ${ }^{\mathrm{d}}$, Kiran Pote ${ }^{\mathrm{b}}$, Pratibha Narang ${ }^{\mathrm{b}}$, \\ R.Vimal Raj ${ }^{\mathrm{e}}$, Praveen Kumar ${ }^{\mathrm{f}}$, Paluru Vijayachari ${ }^{\mathrm{e}}$
}

a Department of Community Medicine, Mahatma Gandhi Institute of Medical Sciences, Sevagram, India

${ }^{\mathrm{b}}$ Department of Microbiology, Mahatma Gandhi Institute of Medical Sciences, Sevagram, India

${ }^{\mathrm{c}}$ Department of Medicine, Mahatma Gandhi Institute of Medical Sciences, Sevagram, India

${ }^{\mathrm{d}}$ Department of Pediatrics, Mahatma Gandhi Institute of Medical Sciences, Sevagram, India

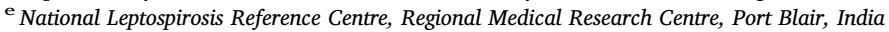

${ }^{\mathrm{f}}$ National Institute for Malaria Research, Dwarka, New Delhi, India

\section{A R T I C L E I N F O}

\section{Keywords:}

Leptospirosis

Spatial epidemiology

Time series Poisson regression

Climatic determinants

Wardha

\begin{abstract}
A B S T R A C T
Hospital-based surveillance of zoonotic diseases was carried out at a tertiary care hospital located in semi-arid zone in Central India. Here, we report descriptive epidemiology and climatic determinants of leptospirosis. All patients presenting with fever of 5 days and more were included in the study. We interviewed the subject to obtain data on socio-demographics. Blood samples were collected and IgM ELISA was carried out to diagnose leptospirosis. Microscopic agglutination test was performed at National Leptospirosis Reference Centre, Port Blair. Data on climatic conditions was obtained from Indian Meteorology Department and National Centre for Environmental Prediction. Time-series Poisson Regression analysis was carried out to study the climatic determinants. We found $12.7 \%$ of the study subjects positive for leptospirosis by IgM ELISA. Positivity was maximum (17.1\%) in 41-60 years of age, more females were affected than males (14\% vs $11.5 \%)$. Farm workers were affected more (17.2\%) than non-farm workers performing service, business, household work etc. (10.9\%). Positivity was more in monsoon as compared to other seasons. We found a single large hot cluster of leptospirosis in the middle of the district. Relative humidity in the month and rainfall in the previous month was the significant determinants of leptospirosis.
\end{abstract}

\section{Introduction}

Leptospirosis is a public health problem in areas where poor agricultural and waste disposal practices lead to contact with Leptospiracontaminated environment. It mimics dengue outbreak because of similarity in clinical presentation, and hence is often overlooked and underreported $^{1,2}$. Globally, more than one million cases ${ }^{3}$ of leptospirosis occur, with more than $10 \%$ mortality. It could be the cause of up to $20 \%$ fever cases of unknown origin ${ }^{4}$. Awareness of the occurrence of leptospirosis in an area can sensitize the medical practitioners and public-health system to initiate appropriate control measures. Hospitalbased surveillance is the first step to generate evidence about the existence of the disease in an area and to understand its epidemiology.

In the present study, hospital-based surveillance of zoonotic disease in Kasturba Hospital, Sewagram, Wardha District was carried out, to generate evidence on the endemicity of leptospirosis in central India, which was otherwise lacking ${ }^{5}$. We present here descriptive epidemiology of the disease, along with its climatic determinants.

\section{Methodology}

\subsection{Study setting}

A hospital-based surveillance of zoonotic diseases (leptospirosis, brucellosis, scrub typhus, listeriosis and bovine tuberculosis) was carried out at Kasturba Hospital, Sewagram, situated in the Wardha district, during the period from July 2015 to June 2016. It is a tertiary care center located in central India. The Wardha district lies between $20^{\circ} 18^{\prime}$ and $21^{\circ} 21^{\prime}$ North latitudes and $78^{\circ} 4^{\prime}$ to $79^{\circ} 15^{\prime}$ East longitudes, and has tropical climate ${ }^{6}$. During monsoon, it is very humid. Health care in this district is provided by 28 Primary Health Centres, 8 Rural Hospitals, 3 sub-divisional hospitals, one district hospital and 2 medical college hospitals ${ }^{7}$. Here, we are presenting our findings on leptospirosis.

\footnotetext{
* Corresponding author at: Mahatma Gandhi Institute of Medical Sciences, Sevagram, 442102, Distt Wardha, Maharashtra, India.

E-mail address: rahulnarang@mgims.ac.in (R. Narang).
} 


\subsection{Study subjects, recruitment and data collection}

Those patients of any age, presenting with fever or history of fever ( $>38^{\circ} \mathrm{C}$ ) of $\geq 5$ days, and were negative for other causes, viz, malaria, dengue and enteric fever, visiting the Kasturba Hospital Sewagram were recruited for the study, after obtaining written informed consent.

Information on socio-demographic characteristics and illness was obtained by personal interview, and $5 \mathrm{ml}$ blood sample was collected by venipuncture in plane bulb for serology. All the specimens were transported to the Microbiology Department, MGIMS, Sewagram for further processing. Serum samples were tested immediately using IgM ELISA and a part of it was sent to National Leptospirosis Reference Centre, Regional Medical Research Centre, Port Blair, India (RMRC Port Blair) on ice packs for carrying out Microscopic Agglutination Test (MAT). Whole blood samples were stored at $-70{ }^{\circ} \mathrm{C}$ till further use.

Data on climatic variables (rainfall, relative humidity, minimum and maximum temperature) were obtained from Indian Meteorology Department and National Centre for Environmental Prediction, NCEP (www.ncep.noaa.gov). Monthly averages for Wardha district were used for analysis after appropriate transformations.

\subsection{Diagnosis of leptospirosis}

Leptospira IgM ELISA kit (Panbio, Republic of Korea) was employed to detect antibodies specific to leptospira species. The assay was performed as per the manufacturer's instructions.

MAT for detection of anti-Leptospira antibodies in serum samples was performed at RMRC, Port Blair as described earlier ${ }^{8,9}$, using a battery of 16 reference strains of Leptospira, and a local isolate, representing 14 serogroups viz., Australis (Ballico), Autumnalis (Bangkinang 1), Canicola (Hond Utrecht IV), Grippotyphosa (Moskva V \& CH31), Icterohaemorrhagiae (RGA \& the local isolate, AF 61), Pomona (Pomona), Sejroe (Hardjoprajitno), Hebdomadis (Hebdomadis), Pyrogenes (Salinem), Cynopteri (3522C'), Javanica (Poi), Bataviae (Swart), Tarassovi (LT-79) and Djasiman (Djasiman). MAT was performed on doubling dilutions of serum, starting from an initial dilution of 1 in 20. Positive samples were titrated up to the end point. (Table 1)

For the presumptive diagnosis following criteria was used- IgM ELISA positive with compatibility of clinical signs and symptoms ${ }^{10}$. MAT results were used to determine the circulating serovars in the area.

\subsection{Data analysis}

Disease magnitude was expressed in percentage and age, sex, geographic location and time distribution has also been presented.

Map function of EPI INFO 7.0 was used to plot the geographic distribution of leptospirosis cases in the district. We used R to carry out point pattern analysis and kriging. Variance Mean Ratio (VMR) was also calculated to find out extent of clustering of cases along with quadrant test. Kernel density analysis was carried out for understanding of clustering phenomenon. Spatial analysis using SaTScan ${ }^{\mathrm{TM}}$ was used to explore hot clusters of Leptospirosis using discrete Poisson modelling ${ }^{11}$. The cases were aggregated with respect to Primary Health Centre areas and town areas, for the purpose of spatial analysis. Kulldorff spatial scan statistics was employed to test for the significance in spatial clustering of Leptospirosis within the hot cluster, as compared to the areas outside the cluster ${ }^{12}$. QGIS 2.18.2 was used to plot the SaTScan output.

Correlation between monthly incidence of Leptospirosis and monthly mean climatic variables (minimum and maximum temperature, relative humidity and rainfall) was analysed using Pearson's correlation coefficient. Highest correlation was used to identify the optimal lag of the climatic condition. Time-series Poisson regression analysis was used to quantify the association between climatic condition and transmission. Number of incident cases of Leptospirosis was assumed to follow Poisson distribution. Regression model used was as follows:

$$
\begin{aligned}
\ln \left(Y_{t}\right)= & \beta_{0}+\beta_{1}{ }^{*} t+\beta_{2}{ }^{*} \text { Humidity }_{t}+\beta_{3}{ }^{*} \text { Rainfall }_{t-1}+\beta_{4} \\
& * \text { Minimum Temperature }{ }_{t-3}+\beta_{5}{ }^{*} \text { Maximum }_{\text {Temperature }} \text { Tex }
\end{aligned}
$$

Where, $\mathrm{Y}_{\mathrm{t}}$ was the number of leptospirosis cases in month $\mathrm{t}$, beta are coefficients of regression equation, while subscripts of climatic variables are the appropriate months that correlated with the number of leptospirosis cases.

Ethical approval was obtained from the Institutional Ethics Committee prior to the study.

\section{Results}

Out of 1680 subjects with fever over a period of five or more days, $636(40 \%)$ were in the age group of $21-40$ years, followed by 374 $(22 \%)$ in the age group of $41-60$ years. Females comprised of $53.6 \%$ and about a quarter were agricultural farm workers. About half (48.9\%) of the fever cases were found to occur during monsoon period. Threefourth was from Wardha district and the rest were from the adjoining districts of Maharashtra and neighbouring states. (Table 2)

We found 213 of 1680 to be positive for IgM ELISA. The prevalence of leptospirosis in the study subjects was $12.7 \%$ based on IgM positivity. Maximum positivity of $17.1 \%$ was in the age group of $41-60$ years, followed by $14.8 \%$ in $21-40$ years of age group. It was $14 \%$ among females as compared to $11.5 \%$ among males. Subjects who worked in agricultural farms were affected more (17.2\%). Positivity in other occupations (service, business and household workers) was $10.9 \%$.

Table 1

\begin{tabular}{|c|c|c|c|c|}
\hline S. No & Serogroup & Serovar & Strain & Genomospecies \\
\hline 1 & Australis & Australis & Ballico & Leptospira interrogans \\
\hline 2 & Autumnalis & Bangkinang & Bangkinang I & Leptospira interrogans \\
\hline 3 & Canicola & Canicola & Hond Uterecht IV & Leptospira interrogans \\
\hline 4 & Grippotyphosa & Grippotyphosa & Moskva V & Leptospira interrogans \\
\hline 5 & Grippotyphosa & Grippotyphosa & CH 31 & Leptospira interrogans \\
\hline 6 & Hebdomadis & Hebdomadis & Hebdomadis & Leptospira interrogans \\
\hline 7 & Icterohaemorrhagiae & Icterohaemorrhagiae & RGA & Leptospira interrogans \\
\hline 8 & Icterohaemorrhagiae & Lai Like & AF 61 & Leptospira interrogans \\
\hline 9 & Pomona & Pomona & Pomona & Leptospira interrogans \\
\hline 10 & Pyrogenes & pyrogenes & Salinem & Leptospira interrogans \\
\hline 11 & Sejroe & Hardjo & Hardjoprajitno & Leptospira interrogans \\
\hline 12 & Cynopteri & Cynopteri & $3522 C^{6}$ & Leptospira krischneri \\
\hline 13 & Javanica & Poi & Poi & Leptospira borgptersenii \\
\hline 14 & Bataviae & Bataviae & Swart & Leptospira interrogans \\
\hline 15 & Tarassovi & Bakeri & LT-79 & Leptospira santarosai \\
\hline 16 & Djasiman & Djasiman & Djasiman & Leptospira interrogans \\
\hline
\end{tabular}

Details of leptospiral serovars used in MAT. 
Table 2

Distribution of leptospirosis with respect to demography (July 2015-June 2016)

\begin{tabular}{|c|c|c|c|}
\hline \multirow[t]{2}{*}{ Variables } & \multicolumn{2}{|l|}{ Leptospirosis } & \multirow[t]{2}{*}{ Total } \\
\hline & Yes & No & \\
\hline Overall & $213(12.7)$ & $1467(87.3)$ & 1680 \\
\hline \multicolumn{4}{|l|}{ Age group (years) } \\
\hline Upto 10 & $5(2.2)$ & $225(97.8)$ & $230(13.7)$ \\
\hline $11-20$ & $26(10.0)$ & $234(90.0)$ & $260(15.5)$ \\
\hline $21-40$ & $94(14.8)$ & $542(85.2)$ & $636(39.9)$ \\
\hline $41-60$ & $64(17.1)$ & 310 (82.9) & $374(22.4)$ \\
\hline$>60$ & $23(13.1)$ & $153(86.9)$ & $176(10.5)$ \\
\hline \multicolumn{4}{|l|}{ Sex } \\
\hline Male & $104(11.5)$ & 797 (88.5) & $779(46.4)$ \\
\hline Female & $109(14.0)$ & $670(86.0)$ & $90153.6)$ \\
\hline \multicolumn{4}{|l|}{ Occupation $(\mathrm{N}=1431)$} \\
\hline Non-Farm workers & 104 (10.9) & $851(89.1)$ & 955 (56.7) \\
\hline Farm workers & $82(17.2)$ & $394(82.8)$ & $476(28.3)$ \\
\hline \multicolumn{4}{|l|}{ Seasons } \\
\hline Winter (Dec-Feb) & $26(7.4)$ & $324(92.6)$ & $350(20.8)$ \\
\hline Summer (March-May) & $15(8.8)$ & $156(91.2)$ & $171(10.2)$ \\
\hline Monsoon (Jun-Sept) & $148(18.0)$ & $674(82.0)$ & $822(48.9)$ \\
\hline Post-monsoon (Oct-Nov) & $24(7.1)$ & 313 (92.9) & $337(20.1)$ \\
\hline \multicolumn{4}{|l|}{ Geographic location } \\
\hline Wardha district & $162(12.9)$ & $1090(87.1)$ & $1252(74.5)$ \\
\hline Adjoining districts and states & $42(9.8)$ & $386(90.2)$ & $428(25.5)$ \\
\hline
\end{tabular}

Highest positivity of $18 \%$ was observed during monsoon season, as compared to other seasons, where the positivity was almost constant and ranged from $7.1 \%$ to $8.8 \%$.

A total of 200 sera (7 paired) were tested for MAT at Port Blair, and results were available for 196 . Considering MAT titres of $\geq 1: 80$ as positive, a total of $121(7.2 \%)$ patients were considered as suspected for Leptospirosis. Serovars detected were; Bakeri (69\%), Djasiman (18\%), Lai Like (5\%), Australis (4\%) and Automnalis, Icterohaemorrhagiae, Pomona and Pyrogenes (one each).

Point pattern analysis of 162 cases from Wardha district was carried out which showed significant clustering of leptospirosis. The VMR was 3.77. Kriging showed highest clustering in the center of the district. Kernel density analysis also showed significant clustering of cases. Spatial scan identified single large cluster of leptospirosis in the center of the district $(20.737906 \mathrm{~N}, 78.707460 \mathrm{E})$ with a radius of $36.8 \mathrm{Km}$. The relative risk of leptospirosis in the hot spot area was 11.67 as compared to the area outside the hotspot (Log likelihood ratio $=71.47$, $\mathrm{p}<0.001$ ). (Fig. 1)

Time-series Poisson regression technique was used to identify the climatic determinants of leptospirosis. The lag time was identified using Pearson correlation coefficients and lag time of a variable with highest correlation coefficient were forced in the model. The highest correlation of the number of leptospirosis cases was found with rainfall during the preceding month (t-1), relative humidity in the month $(\mathrm{t})$, minimum and maximum temperature in the preceding 3rdmonth (t-3). (Table 3) Two risk factors that contributed significantly to the number of leptospirosis cases were relative humidity during the month and rainfall in the previous month. (Table 3) The model fitted well and the predicted number of leptospirosis cases matched during different months. (Fig. 2)

\section{Discussion}

Leptospirosis is a zoonosis with humans as the accidental host. Almost all mammalian species can harbour leptospires in their kidneys and act as a source of infection to human beings and other animals. However, cattle, buffaloes, horses, sheep, goat, pigs, dogs and rodents are the common reservoirs of leptospires. Rodents were the first recognized carriers of leptospires. They are the only major animal species that can shed leptospires throughout their lifespan, without clinical manifestations. They are incriminated as a primary source of infection to human beings. Pigs and cattle can excrete very large number of leptospires in the carrier state (i.e., chronic leptospiral colonization of the renal tubules) and can be an important source for human infection. Leptospires shed through mammal urine, gain access to human body through cuts, abrasions or mucous membrane ${ }^{13}$ and cause infection, which ultimately result in the disease with fever, within 7 days as the main symptom ${ }^{14}$.

In the present study IgM ELISA positivity was considered as presumptive diagnostic test for Leptospirosis. MAT was attempted in all the IgM positive cases to determine serovars. A number of studies from India have demonstrated presence of different serovars in various geographic locations. A study from North India showed presence of serovars Pomona, Ballum, Gryppotyphosa, and Autumnalis ${ }^{15}$. Serovar Copenhageni has been reported from Mumbai and Coastal areas of Maharashtra, while serovars Autumnalis and Copenhageni have been reported from Pune ${ }^{16}$. Another study from Mumbai has reported Pyrogenes, Icterohemorrhagiae, Bataviae, Pomona, Tarrassovi and Canicola as prevalent leptospira serovars in Mumbai ${ }^{17}$. A recent multicentric study from India has reported presence of serovars Australis, Automnalis, Pyrogenes, Janavica, Tarrasovi, Pomona, Hebdomadis, Interohaemorrhagiae and Canicola from different locations ${ }^{18}$. An interesting feature of the present study was demonstration of serovar Bakeri that belongs to Serogroup Tarassovi and species L. santarosai, in $69 \%$ of MAT positive cases. A total of 79 subjects who were IgM ELISA positive were found negative for MAT. This can be explained by the fact that MAT positivity depends upon types of serovars tested while performing MAT. Also, no single MAT titre can be regarded as diagnostic of acute or active infection and sometimes confirmed patients have low MAT titres 10 .

In the present study, leptospirosis was observed in $12.7 \%$ of cases with fever of 5 days and more. Cases with at least 5 days duration were included in the study, as it provides time for the immune system to produce IgM antibodies that are detectable using IgM ELISA. ICMR Task Force Study on Leptospirosis disease burden estimation had reported the magnitude to be $12.74 \%$ in 2003 . In Central India the disease burden was $3.27 \%{ }^{19}$. In a hospital based study in Northern India, the magnitude reported was $11.7 \%$ and $20.5 \%$ in 2004 and 2008 respectively, which indicates a rising trend of the diseas $\mathrm{e}^{20}$.

Single large hot cluster of the leptospirosis was observed in the center of the district. Clustering phenomenon indicates active transmission and higher risk in the population located in the area. Control measures needs to be initiated in the hot cluster on priority basis. This is the area where the study hospital is situated and easy acceptability to the study hospital may have led to this finding. Similar clusters may also be present in the periphery of the district but as the cases from the peripheral areas did not reach study hospital, could not be picked up by this hospital based surveillance. Also, there is no other hospital with diagnostic facility of leptospirosis in the district. Hence, diagnostic facilities of leptospirosis in the peripheral health institutions should be made available. Additionally, it should be made part of health management information system. This may be started with integrated community based surveillance of leptospirosis in humans and pet animals in small geographic area.

The leptospires are shed in animal urine, and in the environment they survive in water or soil and may form biofilms to stay for long periods ${ }^{21}$. The formations of biofilms help the organism to survive in adverse conditions, even though leptospires are fragile organisms ${ }^{22-24}$. When humans come in contact with the environment, contaminated with leptospires, they enter the host. In the present study, maximum occurrence of leptospirosis (18\%) was observed during monsoon season, when large amount of water surface and agricultural activities exist. They were also found in other season but at low level (8\%). This necessitates the health care providers' to be sensitized and warrants continuous control activities. These could include, creating awareness, use of shoes and gloves to avoid contact with contaminated water, 


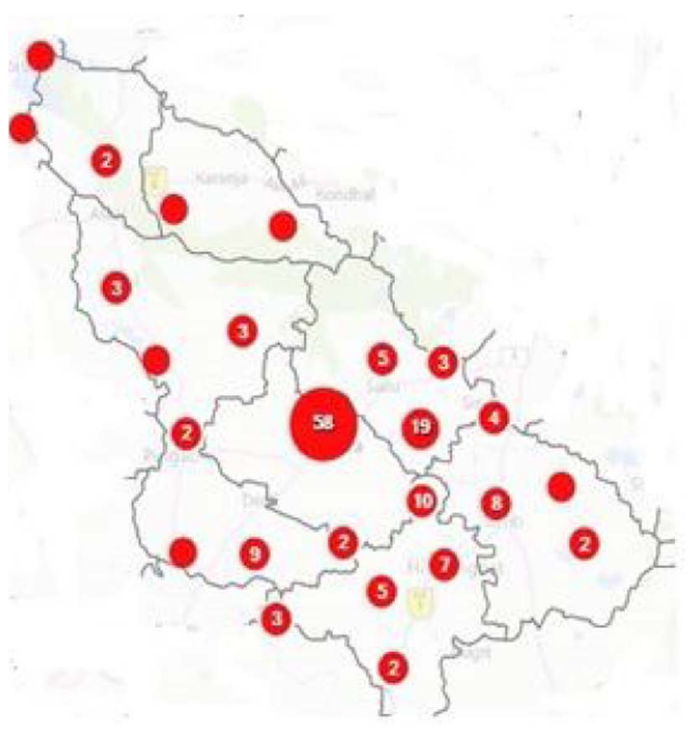

(A)

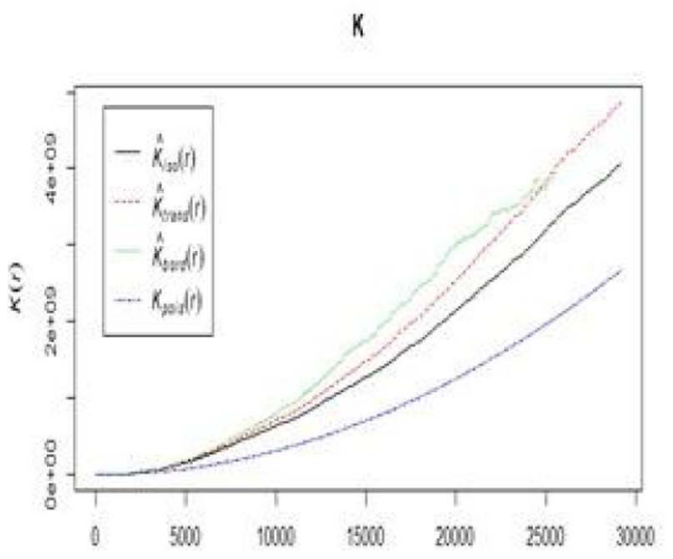

(C)

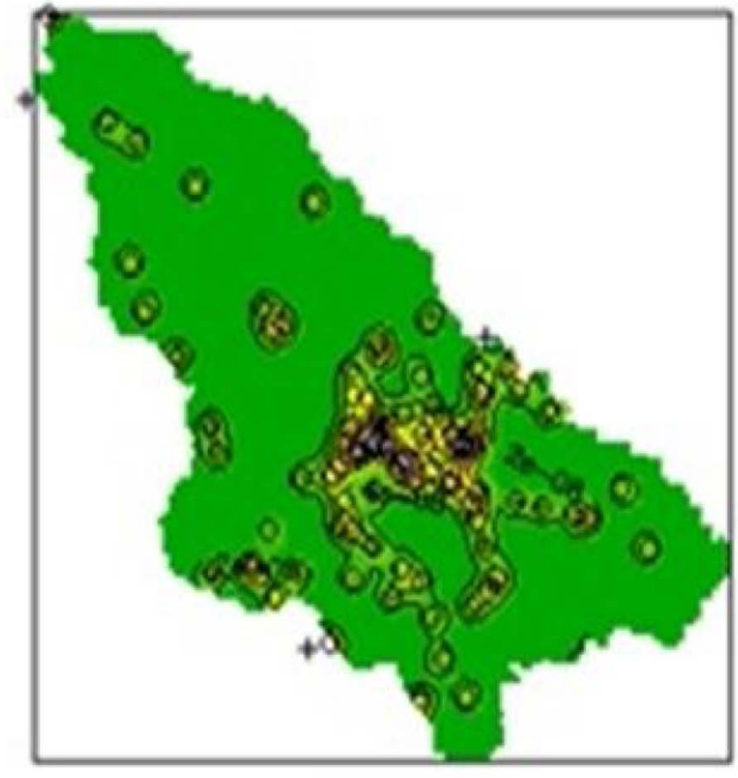

0
0
0
0
0
0
0
0
0
0
0
0

(B)

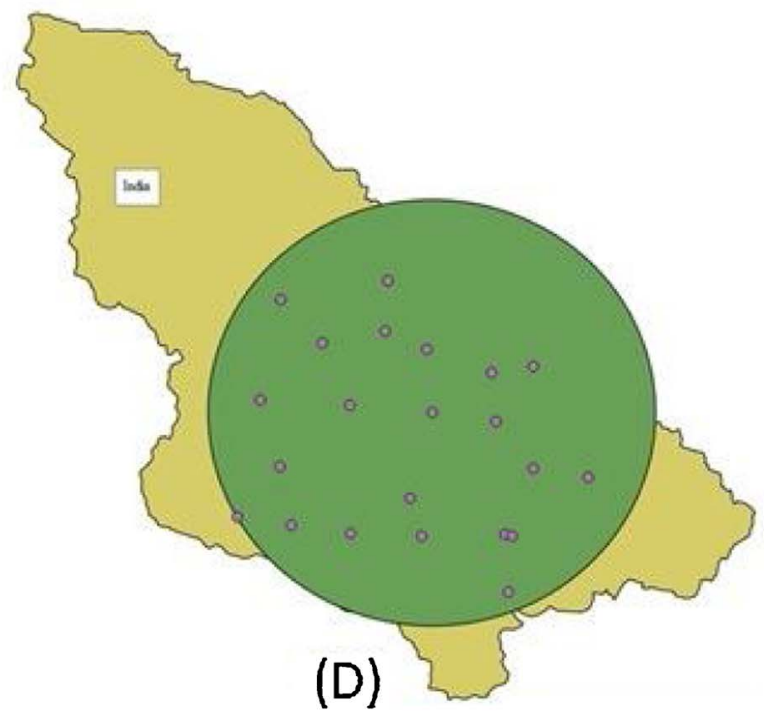

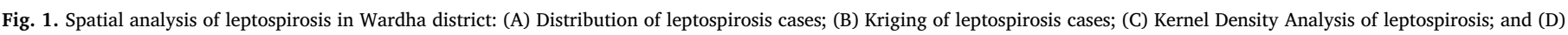
Hot cluster of leptospirosis in Wardha district.

Table 3

Time-series Poisson regression model for prediction of leptospirosis using climatic determinants.

\begin{tabular}{lccc}
\hline Variable & $\operatorname{Exp}(\mathrm{B})$ & $95 \%$ CI of $\operatorname{Exp}(\mathrm{B})$ & $\mathrm{p}$-value \\
\hline Intercept & 1.561 & $0.103-23.673$ & 0.748 \\
Month of the year & 0.886 & $0.725-1.082$ & 0.234 \\
Relative humidity in the month (t) & 1.029 & $1.004-1.055$ & 0.025 \\
Rainfall in the previous month (t-1) & 1.268 & $1.035-1.554$ & 0.022 \\
Minimum temperature of preceding & 0.971 & $0.852-1.106$ & 0.655 \\
$\quad$ 3rdmonth (t-3) & 1.062 & $0.886-1.273$ & 0.515 \\
Maximum temperature of preceding & & & \\
$\quad$ 3rdmonth (t-3) & & &
\end{tabular}

Omnibus test $p$-value $<0.001$ Chi-square $/ \mathrm{df}=0.82$.

rodent control, prevent draining of urine from cattle sheds directly into water bodies and chemoprophylaxis in high risk population residing in hot clusters.

In the present study, highest proportion of leptospirosis was observed in economically productive age group, agricultural workers and females. Wardha district is an agrarian district with animal husbandry as the main income generating activity. Women folk in the area are more involved in taking care of the animals. Hence, they are more exposed to animal urine and thus have more leptospirosis in the district. Majority of the studies have reported this disease to be common among males, while a study from Korea found females to be more affected ${ }^{25}$.

In Wardha district, relative humidity in the month and rainfall in the previous month were the significant determinants of leptospirosis cases in a given month. In another study from Korea it was observed that $1-\mathrm{mm}$ increase in the average weekly rainfall was associated with $2.0 \%$ increase, with a 6 week lag, and a $1 \%$ increase in relative humidity was associated with a maximum decrease of $4 \%$ at lag 0 , and a significant maximum increase of $4 \%$ after an 11 -week lag $^{25}$.

To conclude, leptospirosis was found all through the year in Wardha district of Maharashtra with an overall positivity of $12.7 \%$, and a peak of $18 \%$ in monsoon. Economically productive age group, agricultural workers and females were affected more. Significant clustering 


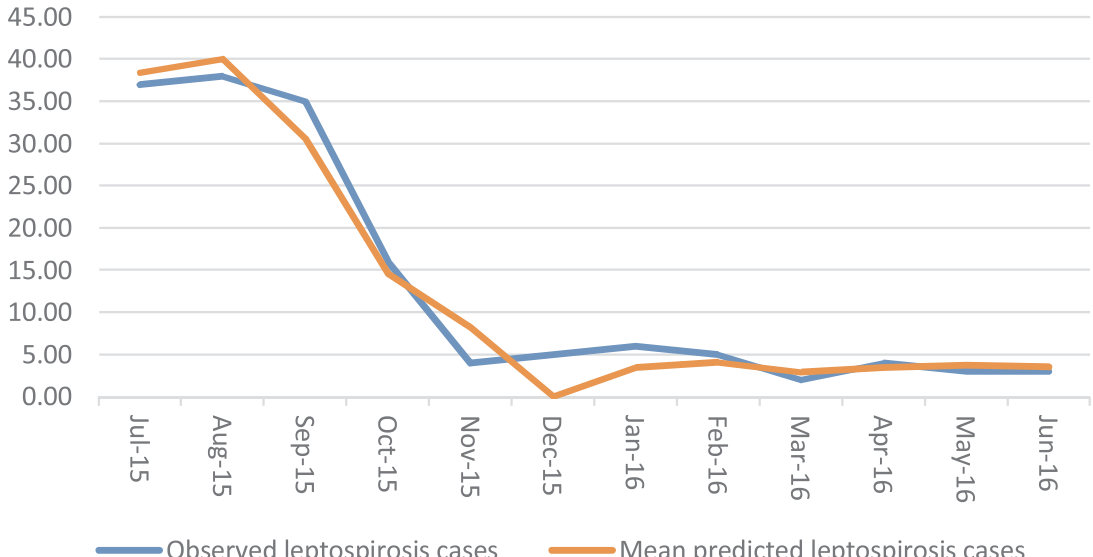

Fig. 2. Observed and expected number of leptospirosis cases.

occurred in the center of the district. Among the climatic determinants, relative humidity during the month and rainfall during the previous month were significantly associated with the occurrence of leptospirosis.

\section{Acknowledgements}

The study was funded by Indian Council of Medical Research, New Delhi vide Grant Letter No. Zon/15/11/2014-ECD-II. We are thankful to MGIMS Sevagram and ICMR Zoonosis Project staff.

\section{References}

1. World Health Organization. Human Leptospirosis: Guidance for Diagnosis, Surveillance and Control. Geneva: World Health Organization; 2003.

2. Fontes RM, Cavalcanti De LPG, Oliveira ACA, Bezerra De LFM, Gomes AMM, Colares JKB, et al. A new possibility for surveillance: do we identify all cases of leptospirosis? Rev Inst Med Trop São Paulo. 2015;57(5):443-446.

3. Costa F, Hagan JE, Calcagno J, Kane M, Torgerson P, Martinez-Silveira MS, et al. Global morbidity and mortality of leptospirosis: a systematic review. small PLC, editor. PLoS Negl Trop Dis. 2015;9:e0003898.

4. World Health Organization. Leptospirosis Burden Epidemiology Reference Group, World Health Organization, Department of Food Safety and Zoonoses, Editors. Report of the First Meeting of the Leptospirosis Burden Epidemiology Reference Group. Geneva, Switzerland: World Health Organization, Department of Food Safety and Zoonoses; 2010.

5. Karande S, Bhatt M, Kelkar A, Kulkarni M, De A, Varaiya A. An observational study to detect leptospirosis in Mumbai, India, 2000. Arch Dis Child. 2003;88(12):1070-1075.

6. Collectorate, Wardha [Internet]. 2017; 2017. ([cited 2017 Aug 28]. Available from: http://wardha.nic.in/).

7. Zilla Parishad Wardha. Zilla Parishad Wardha [Internet]. 2017; 2017. ([cited 2017 Aug 28]. Available from: http://www.zpwardha.in/dpt health_hiwd.php).

8. Wolff JW. hamas CC, ed. The Laboratory Diagnosis of Leptospirosis. Illinois: Springfield; 1954.

9. Vijayachari P, Sugunan AP, Sehgal SC. Evaluation of Microscopic Agglutination Test (MAT) as a diagnostic tool during acute stage of leptospirosis in low and high endemic areas. Indian J Med Res. 2001;114:99-106.

10. Vijayachari P. Leptospirosis Laboratory Manual. World health organization; 2007:44

11. SaTScan - Software for the Spatial, Temporal, and Space-time Scan Statistics [Internet].
2017; 2017. ([cited 2017 Feb 21]. Available from: https://www.satscan.org/).

12. Kulldorff M, Nagarwalla N. Spatial disease clusters: detection and inference. Stat Med. 1995;14(April (8)):799-810.

13. Basker P, Kannan P, Kolandaswamy KG. Study on the prevalence of leptospirosis among fever cases reported from private clinics in the urban areas of Villupuram district, Tamil Nadu, India. Osong Public Health Res Perspect. 2014;5(February (1)):54-67.

14. McBride AJ, Athanazio DA, Reis MG, Ko AI. Leptospirosis. Curr Opin Infect Dis. 2005; 18:376-386

15. Sethi S, Sharma N, Kakkar N, Taneja J, Chatterjee SS, Banga SS, Sharma M. Increasing trends of leptospirosis in northern India: a clinico-epidemiological study. PLoS Negl Trop Dis. 2010;4(1):e579.

16. Bharadwaj R, Bal AM, Joshi SA, Kagal A, Pol SS, Garad G, Arjunwadkar V, Katti R. An urban outbreak of leptospirosis in Mumbai, India. Jpn J Infect Dis. 2002;55(6):194-196.

17. Patil DY, Dahake RV, Chowdhary AS, Deshmukh RA, Roy S, Patil D, Dahake R, Chowdhary A. Clinico-epidemiological observations of human leptospirosis from Mumbai, India. J Infect Public Health. 2017;10(2):247-248.

18. Chandy S, Kirubanandhan L, Hemavathy P, Khadeeja AM, Kurian SJ, Venkataraman K, Mørch K, Mathai D, Manoharan A. Serovar prevalence of Leptospira in semirural India and the development of an IgM-based indirect ELISA. $J$ Infect Dev Countries. 2017;11(03):234-241.

19. Sehgal SC, Sugunan AP, Vijayachari P. Leptospirosis disease burden estimation and surveillance networking in India. Southeast Asian J Trop Med Public Health. 2003;25(September (34)):170-177.

20. Sethi S, Sharma N, Kakkar N, Taneja J, Chatterjee SS, Banga SS, Sharma M. Increasing trends of leptospirosis in northern India: a clinico-epidemiological study. PLoS Negl Trop Dis. 2010;12;4(January (1)):e579.

21. Ristow P, Bourhy P, Kerneis S, Schmitt C, Prevost MC, Lilenbaum W, Picardeau M. Biofilm formation by saprophytic and pathogenic leptospires. Microbiology. 2008;154(May (5)):1309-1317.

22. Espeland EM, Wetzel RG. Complexation, stabilization, and UV photolysis of extracellular and surface-bound glucosidase and alkaline phosphatase: implications for biofilm microbiota. Microb Ecol. 2001;42(December (4)):572-585.

23. Teitzel GM, Parsek MR. Heavy metal resistance of biofilm and planktonic Pseudomonas aeruginosa. Appl Environ Microbiol. 2003;69(April (1)):2313-2320.

24. McNeill K, Hamilton IR. Acid tolerance response of biofilm cells of Streptococcus mutans. FEMS Microbiol Lett. 2003;221(April (1)):25-30.

25. Joshi YP, Kim EH, Cheong HK. The influence of climatic factors on the development of hemorrhagic fever with renal syndrome and leptospirosis during the peak season in Korea: an ecologic study. BMC Infect Dis. 2017;7;17(June (1)):406. 